\title{
Comparative Study of Rapid Diagnostic Test Versus Elisa For HIV Detection At Blood Bank In Tertiary Care Hospital
}

\author{
Authors \\ Dr Parth R.Goswami, Dr Jitendra J. Chavda \\ MD Pathology, Department of Pathology, Government Medical College, Bhavnagar \\ Corresponding Author \\ Dr Parth R.Goswami \\ "102” Sangath flat, Shilpinagar, Kalanala, Bhavnagar-364001 \\ Email: goswamiparth42@gmail.com, Mobile number: 9099097923
}

\begin{abstract}
BACKGROUND: Human immunodeficiency virus leads to development of AIDS which is one of the major public health problem worldwide. ${ }^{1,2}$ So it is necessary to diagnose HIV as early as possible for prevention of HIV spread in community

AIM: This study help us to evaluate effectiveness of rapid diagnostic kits as compared to ELISA methods. MATERIALS AND METHODS: This study was carried out at tertiary care hospitals (blood bank), Gujarat, India from the date 01/01/2016 to 31/07/2016. We have tested total 9111 donor samples with using fourth generation ELISA kit as well as Rapid diagnostic kit.

RESULTS: Rapid diagnostic tests having Sensitivity of $90.90 \%$. specificity was 100\%,positive predictive value $100 \%$ and negative predictive value $99.98 \%$. and accuracy was $99.98 \%$.

CONCLUSION: The rapid diagnostic HIV kits assay gives result in 15 minute can be used in emergency situations when there is less time available to perform ELISA test. So as sensitivity and specitivity of rapid diagnostic tests are high it can be used in emergency situation whenever needed

KEYWORDS: ELISA, Human immunodeficiency virus, p24 antigen, Rapid diagnostic test.
\end{abstract}

\section{INTRODUCTION}

Human immunodeficiency virus leads to development of AIDS which is one of the major public health problem worldwide. ${ }^{1,2}$ So it is necessary to diagnose HIV as early as possible for prevention of HIV spread in community. ${ }^{3}$

Laboratory methods for diagnosis of HIV can be in the form of three way: detection of antigen, detection of antibody and nucleic acid testing. ${ }^{4}$ In our blood bank (where this study carried out)for screening of blood donor samples we are using ELISA $4^{\text {th }}$ generation kit which is efficient and low costing as compare to nucleic acid testing ${ }^{5}$

Rapid diagnostic kits also used for testing donor samples when it is necessary to screen donor immediately before apheresis procedures and when urgent need of fresh blood required .HIV diagnostic test are widely used in India but data regarding 
evaluation is limited. So this study helps us to evaluate effectiveness of rapid diagnostic kits as compared to ELISA methods.

\section{MATERIALS AND METHODS}

This study was carried out at tertiary care hospitals (blood bank),Gujarat, India from the date 01/01/2016 to 31/07/2016.We have tested total 9111 donor samples with using fourth generation ELISA kit as well as Rapid diagnostic kit. Rapid diagnostic card is a solid phase immunochromatographic assay for the qualitative detection of antibody against HIV1(gp 120 plus gp41) and HIV2(gp 36) in human serum or plasma .ELISA fourth generation test kit detect p24 antigen along with detection of antibody against gp41 and gp36 that representing both HIV1 and HIV 2.

When ELISA test for HIV was reactive, it was tested again by another person in duplicate to prevent bias and confirm HIV positivity. Fourth generation ELISA having advantage that it decreases window period (mean reduction 5 to 7 days) that is main limitation in third generation kits. ${ }^{6,7,8,9,10}$ We have also calculated sensitivity and specificity for Rapid diagnostic test in comparison with ELISA method to evaluate its efficacy for use in urgency.

\section{RESULTS}

Among the screening of 9111 donors, total reactive result for HIV by ELISA was 11 in number.All reactive results were confirmed in duplicate result by another person. Among this 11 reactive donor, all were also reactive for rapid card test except 1 donor which showed negative card test. Results were tabulated as below.

TABLE NO.1 COMPARATIVE ANALYSIS OF RAPID VERSUS ELISA

\begin{tabular}{|l|c|c|}
\hline \multirow{2}{*}{ Rapid Card Test } & \multicolumn{2}{|c|}{ Elisa Test Result } \\
\cline { 2 - 3 } & Reactive & Non-Reactive \\
\hline Reactive & 10 & 0 \\
\hline Non-Reactive & 01 & 9100 \\
\hline
\end{tabular}

Here according to above results we have calculated sensitivity, specificity, positive predictive value and negative predictive value according to their formulas.

Sensitivity was $90.90 \%$, specificity was $100 \%$, positive predictive value $100 \%$ and negative predictive value $99.98 \%$.

The accuracy of rapid diagnostic test is $99.98 \%$.

\section{DISCUSSION}

Fourth generation ELISA detect P24 antigen as well as antibody, so reducing the window period and early detection of HIV infection, so early counseling and treatment can be done to stop spreading infection.

The studies are available that compare $3^{\text {rd }}$ and $4^{\text {th }}$ generation ELISA ${ }^{11,12,13}$ but only few data available regarding comparison of rapid kit versus ELISA testing. Sensitivity and specificity of test has to be calculated because rapid kits are used in emergency testing of donor like before aphaeresis procedure or when urgent need for fresh blood is there where 6 to 7 hour not available for testing.

The one donor sample that was non-reactive by rapid card test may be due to low titer of antibody that cannot be detected by rapid card test. The fourth generation ELISA test is having high sensitivity, higher specificity and with incorporation of p24 antigen detection reduce window period as well. The disadvantage of ELISA is time consuming required special expatriation and instrumentation. So it is not a method of choice in emergency situation. However it is the perfect screening test for blood donors in routine HIV testing. The rapid diagnostic test having comparable sensitivity and specificity to that of ELISA and less time consuming can be most useful in emergency conditions.

\section{CONCLUSION}

The rapid diagnostic HIV kits assay gives result in 15 minute can be used in emergency situations when there is less time available to perform ELISA 


\section{JMSCR Vol||04||Issue||08||Page 11870-11872||August}

test. So as sensitivity and specificity of rapid diagnostic tests are high it can be used in emergency situation whenever needed.

\section{CONFLICT OF INTEREST: None}

\section{REFERENCE}

1. United States Centers for Disease control and Prevention. HIV Surveillance - United States, 1981-2008. 2012.

2. WHO Report. Global Summary of the AIDS epidemic. World Health Organization 2009 Available from: http://www.who.int/hiv/data/2009_global_summary.png

3. Cohen T, Corbett EL. Test and treat in HIV: Success could depend on rapid detection. Lancet 2011;378:204-6.

4. Metcalf JA, Davey RT, Lane HC. Acquired immunodefi- ciency syndrome: serologic and virologic tests. In: Devita VT, Hellman S, Rosenberg SA, eds. AIDS: biology, diagnosis, treatment and prevention, 4th edn. Philadelphia: Lippincott Raven, 1997; 177195

5. Zhou H, Jiang CW, Li SJ, Li H, Huang MQ, Liang JQ, et al. Evaluation of four kits for screening HIV antibody. Zhonghua Yu Fang Yi Xue Za Zhi 2010;44:247-50.

6. Brust S, Duttmann $\mathrm{H}$, Feldner $\mathrm{J}$ et al. Shortening of the diagnostic window with the new combined HIV p24 antigen and anti-HIV-1 / 2 / O screening test. J Virol Methods 2000; 90: 153-165.

7. Laperche S, Maniez-Montreuil M, Courouce' AM. Screening tests combined with p24 antigen and anti-HIV antibodies in early detection of HIV-1. Transfus Clin Biol 2000; 7(suppl 1): S18-S24.

8. Gu“rtler L, Mu“hlbacher A, Michl U et al. Reduction of the diagnostic window with a new combined p24 antigen and human immunodeficiency virus antibody screening assay. J Virol Methods 1998; 75: 27-38.

9. Ly TD, Laperche S, Courouce' AM. Early detection of human immunodeficiency virus infection using third- and fourth-generation screening assays. Eur J Clin Microbiol Infect Dis 2001; 20: 104-110.

10. Weber B, Fall EMB, Berger A, Doerr HW. Reduction of diagnostic window by new fourth-generation human immunodeficiency virus screening assays. J Clin Microbiol 1998; 36: 2235-2239

11. Ly TD, Martin L, Daghfal M et al. Seven human immunodeficiency virus (HIV) antigen-antibody combination assays: evaluation of HIV seroconversion sensitivity and subtype detection. J Clin Microbiol 2001; 39: 3122-3128

12. Saville RD, Constantine NT, Cleghorn FR et al. Fourthgeneration enzyme-linked immunosorbent assay for the simultaneous detection of human immunodeficiency virus antigen and antibody. J Clin Microbiol 2001; 39: 2518-2524.

13. Van Binsbergen J, Siebelink A, Jacobs A et al. Improved performance in seroconversion with a 4th generation HIV antigen/antibody assay. J Virol Methods 1999; 82: 77-84. 